\title{
DEFICIT IRRIGATION DOES NOT AFFECT ALTERNATE BEARING OF 'VALENCIA' ORANGE TREES
}

Riccardo Lo Bianco, Filipa S. Grilo

Department of Agricultural, Food and Forest Sciences, University of Palermo, Viale delle Scienze, 90128 Palermo, Italy

Amr Mossad

Agricultural Engineering Department, King Saud University, Riyadh 11451, Kingdom of Saudi Arabia; Agricultural Engineering Department, Ain Shams University, Cairo 11241, Egypt

\begin{abstract}
This study evaluated the effect of long-term partial root zone drying and continuous deficit irrigation on the degree of alternate bearing of adult 'Valencia' orange trees grown in northern Sicily. Three irrigation strategies were imposed in summer from 2007 to 2011: Irrigation with volumes corresponding to $100 \%$ of crop evapotranspiration applied to entire rootzone (CI), partial rootzone drying (PRD) with $50 \%$ of CI water applied to one alternated side of the rootzone, and continuous deficit irrigation (CDI) with $50 \%$ of CI water applied to both sides of the rootzone. The experiment was conducted on 48 adult orange trees arranged according to a randomized block design. Weather and soil parameters were monitored continuously in the field. Plant water status and shoot growth were monitored regularly throughout the seasons. Fruit weight and number were recorded every year at harvest. Alternate bearing index (ABI) was calculated as a measure of the intensity of alternation in each tree in terms of yield, number of fruits, and kilos of fruit per unit of irrigation water applied (IWP). All trees in trial exhibited the typical alternation of biennial bearing. As a general effect, CDI significantly reduced leaf relative water content (RWC), stomatal conductance and fruit size and yield, but not fruit number. PRD significantly reduced stomatal conductance, but induced intermediate RWC and yield, between CI and CDI. A negative but non-linear relationship was found between shoot growth rate and fruit yield. In spite of any reduction of leaf hydration and yield, deficit irrigation did not affect $\mathrm{ABI}$, and trees under all treatments exhibited a similar degree of alternation in terms of yield $(A B I=0.39)$, number of fruits $(A B I=0.44)$ or IWP $(A B I=0.40)$. These results show that biennial bearing of 'Valencia' orange trees is not related to water supply at the tested levels, suggesting that it may not depend on any possible change in carbohydrate reserves or abscisic acid production generated by water deficit.
\end{abstract}

Keywords: biennial bearing, fruit yield, partial rootzone drying, relative water content, stomatal conductance 


\section{INTRODUCTION}

'Valencia' is a late orange cultivar in which fruit develop across a 12- to 14month-period, ranging from fruit-set in late spring of the current year to full ripening in the next spring. This means that for a short time we can find flowers and even fruits at stage I and stage III (Iglesias et al., 2007) on the same tree. For this peculiar circumstance, the presence of older fruits may reduce fruit set or growth of young fruitlets due to competition for resources. Because of competition for nutrients, many fruits abscise during growth (Mehouachi et al., 1995). Furthermore, several endogenous and exogenous factors are likely involved in the high abscission rate occurring in this period (Iglesias et al., 2007). High crop load diminishes flower induction and next-season crop load (Prado et al., 2007; Valiente and Albrigo, 2004) generating the typical biennial bearing pattern. Both crop load level and permanence of mature fruit on the tree have been related to the severity of alternate bearing in 'Valencia' trees, but the mechanism has been associated to hormonal signaling (i.e. ABA level in dormant buds; Jones et al., 1976) rather than to carbohydrate limitations (Jones et al., 1974). In other Citrus spp., alternate bearing seems to be tightly associated with starch and carbohydrate reserves (Shaffer et al., 1985; Goldschmidt and Golomb, 1982).

Regulated deficit irrigation (RDI) is an irrigation practice where trees are irrigated with an amount of water lower than ET at specific times during the season. Overall, RDI is addressed as an efficient water management strategy to optimize water resources (Navarro et al., 2010) and concurrently increase crop productivity (English, 1990). Another deficit irrigation strategy is partial rootzone drying (PRD), which is designed to maintain half of the root system in drying soil, while the other half is irrigated. The theory behind PRD is based on both chemical and hydraulic signaling in drying soil. Under soil moisture deficit conditions, for example, roots produce chemical signals such as ABA which are transported via xylem to the leaves, causing a partial stomatal closure (Davies et al., 2002; Gowing et al., 1990; Kang and Zhang, 2004; Lo Bianco and Francaviglia, 2012). PRD also involves the exposure of roots to alternate drying and wetting cycles which avoid root death and maintain reduced stomatal conductance without visible signs of dehydration (Davies et al., 2002; Kang and Zhang, 2004; Lo Bianco and Francaviglia, 2012). In addition, PRD also improves water use efficiency and irrigation water productivity in various fruit species (Cifre et al., 2005; Romero et al., 2006, García-Tejero et al., 2011; Francaviglia et al., 2013; Talluto et al., 2007, 2008). Nevertheless, the underlying mechanisms of PRD functioning are still a matter of discussion. Field trials with grapes and apple have shown that PRD irrigation may reduce the need of pruning due to an induced low vegetative vigor (Chaves et al., 2007; Talluto et al., 2008). Low vigor increases light penetration which, in turn, increases flower induction and fruit quality.

The possible interaction between deficit irrigation and alternate bearing may be of particular interest for the correct management of 'Valencia' orange trees, but is by far underinvestigated. Possible yield and vegetative growth reductions caused by water deficit could either alleviate or increase alternate bearing, depending on the underlying mechanisms. Hence, the purpose of the present work was to study the interaction between deficit irrigation and alternate bearing of adult 'Valencia' orange trees under Mediterranean conditions.

\section{MATERIALS AND METHODS}

The study was carried out on adult orange trees (Citrus sinensis, L. Osbeck, cv. Valencia) grafted on sour orange (Citrus aurantium L.) in an experimental 
orchard at the Department of Agricultural and Forest Sciences, University of Palermo. Trees were trained to globe-shaped, raised canopy, topped at about $2.5 \mathrm{~m}$ and spaced at $4 \mathrm{~m} \times 4 \mathrm{~m}$. All trees received the same cultural cares except for irrigation. From 2007 to 2011, three irrigation treatments were imposed to 48 trees in the experimental plot: CI, with volumes corresponding to $100 \%$ of crop evapotranspiration $\left(K_{\mathrm{c}}=0.65\right.$ from June to September; $K_{\mathrm{c}}=0.7$ from October to May) applied to the entire rootzone, PRD with $50 \%$ of CI water applied to one alternated side of the rootzone, and CDI with $50 \%$ of CI water applied to both sides of the rootzone. Average irrigation volumes during the five seasons were 387, 175, and $186 \mathrm{~mm}$ for CI, PRD and CDI, respectively. Irrigation volumes were applied in 20 to 26 events from June to September.

Climate data were recorded with a weather station (PESSL Instruments, Austria) positioned in the experimental plot. Soil water potential (SWP) was monitored continuously at $45 \mathrm{~cm}$ depth with Watermark sensors in six locations (Irrometer Co., Riverside, CA, USA) connected to data logger of the weather station. Measures of leaf stomatal conductance (using an AP4 Delta-T porometer, Delta-T Devices, Cambridge, UK) and relative water content (RWC) were made biweekly throughout the irrigation seasons. The integrals of soil water deficit (SWD, difference between the SWP at field capacity and the actual SWP), leaf water saturation deficit (LWSD = $100-$ RWC) and stomatal conductance measures were calculated across each season.

Fruit and shoot growth was also monitored during the irrigation seasons. In all five years of trial, fruits were harvested in May, counted and weighed to determine yield and crop load. An alternate bearing index (ABI) based on yield, crop load and irrigation water productivity (IWP, $\mathrm{kg} \mathrm{m}^{-3}$ ) was calculated according to the following equation:

$$
\mathbf{A B I}=\frac{1}{\mathrm{n}-1}\left(\frac{\mathrm{a} 2-\mathrm{a} 1}{\mathrm{a} 2+\mathrm{a} 1}+\frac{\mathrm{a} 3-\mathrm{a} 2}{\mathrm{a} 3+\mathrm{a} 2}+\frac{\mathrm{a} 4-\mathrm{a} 3}{\mathrm{a} 4+\mathrm{a} 3}+\ldots .+\frac{\mathrm{an}-\mathrm{an}-1}{\mathrm{an}+\mathrm{an}-1}\right)
$$

where $\mathrm{n}$ is the number of years and a was yield, crop load or IWP of each tree in each season. Data were analyzed using analysis of variance and least square regression procedures.

\section{RESULTS AND DISCUSSION}

In the years 2007-2011, annual rainfall ranged from 456 to $1238 \mathrm{~mm}$ (average $743 \mathrm{~mm}$ ) and annual reference evapotranspiration $\left(\mathrm{ET}_{0}\right)$ was $1120 \mathrm{~mm}$, with an average water deficit (rain- $\mathrm{ET}_{0}$ ) of $-597 \mathrm{~mm}$ in the summer months. On an average across years (2007-2011), the impact of deficit irrigation on PRD trees was in between CI and CDI, experiencing 29\% less SWD and 12\% less LWSD than CDI. Likely, differences in SWD between CDI and PRD were mainly due to a greater wetted soil surface, and consequent soil evaporation, as well as to a shallower depth of the wetted soil in the CDI trees (Marsal et al. 2008). This must have been responsible also for the differences in LWSD between the two deficit irrigation treatments. On the other hand, PRD and CDI showed similar reductions (about $15 \%)$ of stomatal conductance $\left(g_{\mathrm{s}}\right)$ over CI. This lack of differences in $g_{\mathrm{s}}$ between PRD and CDI (along with greater leaf hydration in PRD than in CDI) despite of the greater SWD in CDI than in PRD is a clear evidence of an irrigation placement effect (or PRD effect) (Lo Bianco and Francaviglia, 2012).

Average fruit load across the years of trial was about 207 fruits/tree for all irrigation treatments $(\mathrm{P}=0.368)$. During the five years of trial, trees exhibited the typical alternate bearing of 'Valencia' orange with yields ranging from 12 to 50 kg/tree and 2009 and 2011 as off-years (Fig. 1). Only CDI (26.3 kg/tree), not PRD $(27.4 \mathrm{~kg} /$ tree $)$, significantly reduced yields by $17 \%$ over $\mathrm{CI}(31.8 \mathrm{~kg} / \mathrm{tree}, \mathrm{P}=$ 
0.045). Yield reductions in CDI were mainly due to reduced fruit growth rather than fruit number. Shoot growth was not affected by irrigation (data not shown). Regardless of the yield parameter used for calculations, ABI was always similar for the three irrigation treatments (Tab. 1).

As expected, an inverse linear relationship was found between yield and fruit size (Fig. 2) indicating some fruit growth limitation due to competition for resources among fruits. This is a common response in citrus and other fruit tree species, attributed to source limitation, sink competition and some degree of branch autonomy (Guardiola and Garcia-Luis, 2000). Yield per tree was also inversely related to shoot elongation rate, and the inhibitory effect of crop load on vegetative and reproductive development has been related to hormonal changes (mainly GA) and carbohydrate competition (Goldschmidt et al., 1985). In our case, the relationship followed a non-linear trend (Fig. 3), suggesting some threshold mechanism of shoot growth limitation by crop load. Analysis of covariance indicated no effect of the irrigation treatment on either of these two relationships (Figs. 2 and 3).

\section{CONCLUSIONS}

The results of the present study show that biennial bearing of 'Valencia' orange trees is not related to water supply at the tested levels. Nevertheless, reductions of starch and sucrose have been documented in 'Valencia' trees under water deficit (Vu and Yelenoski, 1989); also, PRD or simple water deficit is expected to increase leaf ABA (Dodd et al., 2008). Accordingly, the results of the present study suggest that changes in carbohydrate reserves or abscisic acid alone may not be responsible for alternate bearing in 'Valencia' oranges.

\section{Literature Cited}

Chaves, M., Santos, T., Souza, C., Ortuño, M., Rodrigues, M., Lopes, C., Maroco, J. and Pereira, J. (2007). Deficit irrigation in grapevine improves water-use efficiency while controlling vigour and production quality. Ann. Appl. Biol. 150, 237-252.

Cifre, J., Bota, J., Escalona, J., Medrano, H. and Flexas, J. (2005). Physiological tools for irrigation scheduling in grapevine (Vitis vinifera L.). Agric. Ecosyst. Environ. 106, 159-170.

Davies, W.J., Wilkinson, S. and Loveys, B. (2002). Stomatal control by chemical signalling and the exploitation of this mechanism to increase water use efficiency in agriculture. New Phytol. 153, 449-460.

Dodd, I.C., Egea, G. and Davies, W.J. (2008). ABA signalling when soil moisture is heterogeneous: decreased photoperiod sap flow from drying roots limit ABA export to the shoots. Plant Cell Environ. 31, 1263-1274.

English, M. (1990). Deficit irrigation. I: Analytical framework. J. Irrig. Drain. E-Asce 116, 399-412.

Francaviglia, D., Farina, V., Avellone, G. and Lo Bianco, R. (2013). Fruit yield and quality responses of apple cvars gala and fuji to partial rootzone drying under Mediterranean conditions. J. Agric. Sci. 151, 556-569.

García-Tejero, I., Durán-Zuazo, V.H., Jiménez-Bocanegra, J.A. and Muriel-Fernández, J.L. (2011). Improved wateruse efficiency by deficit-irrigation programmes: implications for saving water in citrus orchards. Sci. Hortic. 128, 274-282.

Goldschmidt, E.E. and Golomb, A. (1982). The carbohydrate balance of alternate-bearing citrus trees and the significance of reserves for flowering and fruiting. J. Amer. Soc. Hort. Sci. 107, 206-208.

Goldschmidt, E.E., Aschkenazi, N., Herzano, Y., Schaffer, A.A. and Monselise, S.P. (1985). A role for carbohydrate levels in the control of fl owering in citrus. Sci. Hort. 26, 159-166.

Gowing, D.J.G., Davies, W.J. and Jones, H.G. (1990). A positive root-sourced signal as an indicator of soil drying in apple, Malus x domestica Borkh. J. Exp. Bot. 41, 1535-1540.

Guardiola, J.L. and García-Luis, A. (2000). Increasing fruit size in Citrus. Thinning and stimulation of fruit growth. Plant Growth Regul. 31:121-132.

Iglesias, D.J., Cercós, M., Colmenero-Flores, J.M., Naranjo, M.A., Ríos, G., Carrera, E., Ruiz-Rivero, O., Lliso, I., Morillon, R., Tadeo, F.R. and Talon, M. 2007. Physiology of citrus fruiting. Braz. J. Plant Physiol. 19, 333-362.

Jones, W.W., Coggins, C.W. and Embleton, T.W. (1976). Endogenous abscisic acid in relation to bud growth in 
alternate bearing 'Valencia' orange. Plant Physiol. 58, 681-682.

Jones, W.W., Embleton, T.W., Barnhart, E.L. and Cree, C.B. (1974). Effect of time and amount of fruit thinning on leaf carbohydrates and fruit set in Valencia oranges. Hilgardia 42, 441-449.

Kang, S. and Zhang, J. (2004). Controlled alternate partial root-zone irrigation: its physiological consequences and impact on water use efficiency. J. Exp. Bot. 55, 2437-2446.

Lo Bianco, R. and Francaviglia, D. (2012). Comparative responses of 'Gala' and 'Fuji' apple trees to deficit irrigation: Placement versus volume effects. Plant Soil 357, 41-58.

Mehouachi, J., Serna, D., Zaragoza, S., Agustí, M., Talon, M. and Primo-Millo, E. (1995). Defoliation increases fruit abscission and reduces carbohydrate levels in developing fruits and woody tissues of Citrus unshiu. Plant Sci. 107, 189-97.

Navarro, J.M., Pérez-Pérez, J.G., Romero, P. and Botía, P. (2010). Analysis of the changes in quality in mandarin fruit, produced by deficit irrigation treatments. Food Chem. 119, 1591-96.

Prado, A.K.S., Machado, E.C., Medina, C.L., Fávero, D. and Mazzafera. P. (2007). Florescimento e frutificação em laranjeiras 'Valencia' com diferentes cargas de frutos e submetidas ou não à irrigação. Bragantia 66, $173-82$.

Romero, P., Navarro, J.M., Perez-Perez, J., García-Sánchez, F., Gómez-Gómez, A., Porras, I., Martinez, V. and Botía, P. (2006). Deficit irrigation and rootstock: their effects on water relations, vegetative development, yield, fruit quality and mineral nutrition of Clemenules mandarin. Tree Physiol. 26, 1537-1548.

Schaffer, A.A., Goldschmidt, E.E., Goren, R. and Galili, D. (1985). Fruit set and carbohydrate status in alternate and nonalternate bearing Citrus cultivars. J. Amer. Soc. Hort. Sci, 110, 574-578.

Talluto, G., Farina, V. and Lo Bianco, R. (2007). Growth, fruit yield and quality of 'Golden Delicious' apple trees under fixed partial rootzone drying. J. Appl. Hortic. 9, 50-55.

Talluto, G., Farina, V., Volpe, G. and Lo Bianco, R. (2008). Effects of partial rootzone drying and rootstock vigour on growth and fruit quality of 'Pink Lady' apple trees in Mediterranean environments. Aust. J. Agric. Res. 59, 785-94.

Valiente, J.I. and Albrigo, L.G. (2004). Flower bud induction of sweet orange trees [Citrus sinensis (L.) Osbeck]: effect of low temperatures, crop load, and bud age. J. Amer. Soc. Hort. Sci. 129, 158-64.

Vu, J.C.V. and Yelenosky, G. (1989). Non-structural carbohydrate concentrations in leaves of 'Valencia' orange subjected to water deficits. Environ. Exp. Bot. 29, 149-154. 
Table 1. Alternate bearing indexes calculated using yield ( $\mathrm{kg} / \mathrm{tree})$, number of fruits per tree, or irrigation water productivity (IWP, $\mathrm{kg} / \mathrm{m}^{3}$ ) of 'Valencia' orange trees under conventional irrigation (CI), partial rootzone drying (PRD) and continuous deficit irrigation (CDI). The $\mathrm{P}$ value indicates the probability associated with the analysis of variance.

\begin{tabular}{cccc}
\hline & Yield & N. fruit & IWP \\
\hline CI & 0.39 & 0.44 & 0.41 \\
PRD & 0.38 & 0.46 & 0.38 \\
CDI & 0.40 & 0.44 & 0.41 \\
\hline$P$ value & 0.940 & 0.897 & 0.775 \\
\hline
\end{tabular}

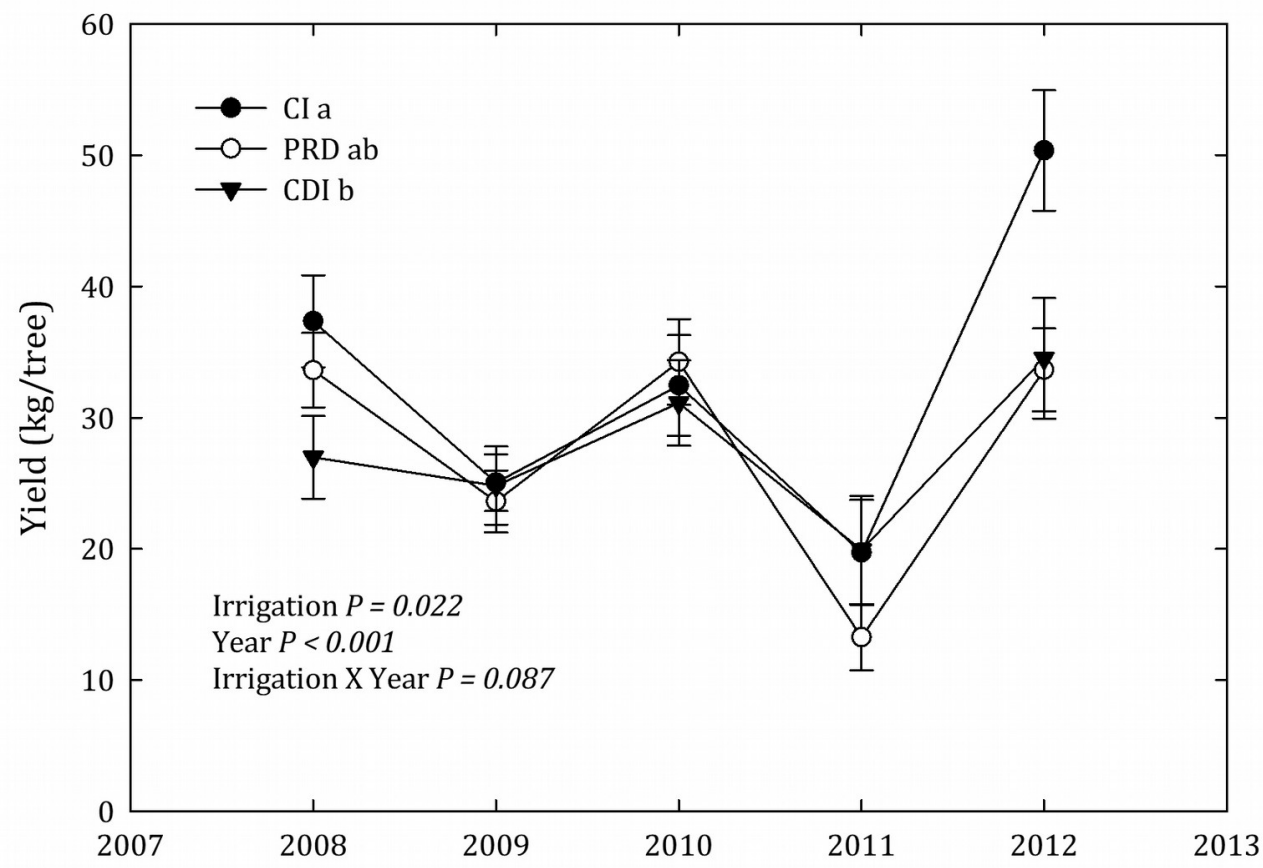

Fig. 1. Yields of 'Valencia' orange trees under conventional irrigation (CI), partial rootzone drying (PRD) and continuous deficit irrigation (CDI) during the five years of trial. The $P$ values indicate the probability associated factors from the analysis of variance. Error bars represent standard errors of the means $(\mathrm{n}=16)$. Different letters in the graph legend indicate significant differences according to Tukey's multiple range test $(P<0.05)$. 


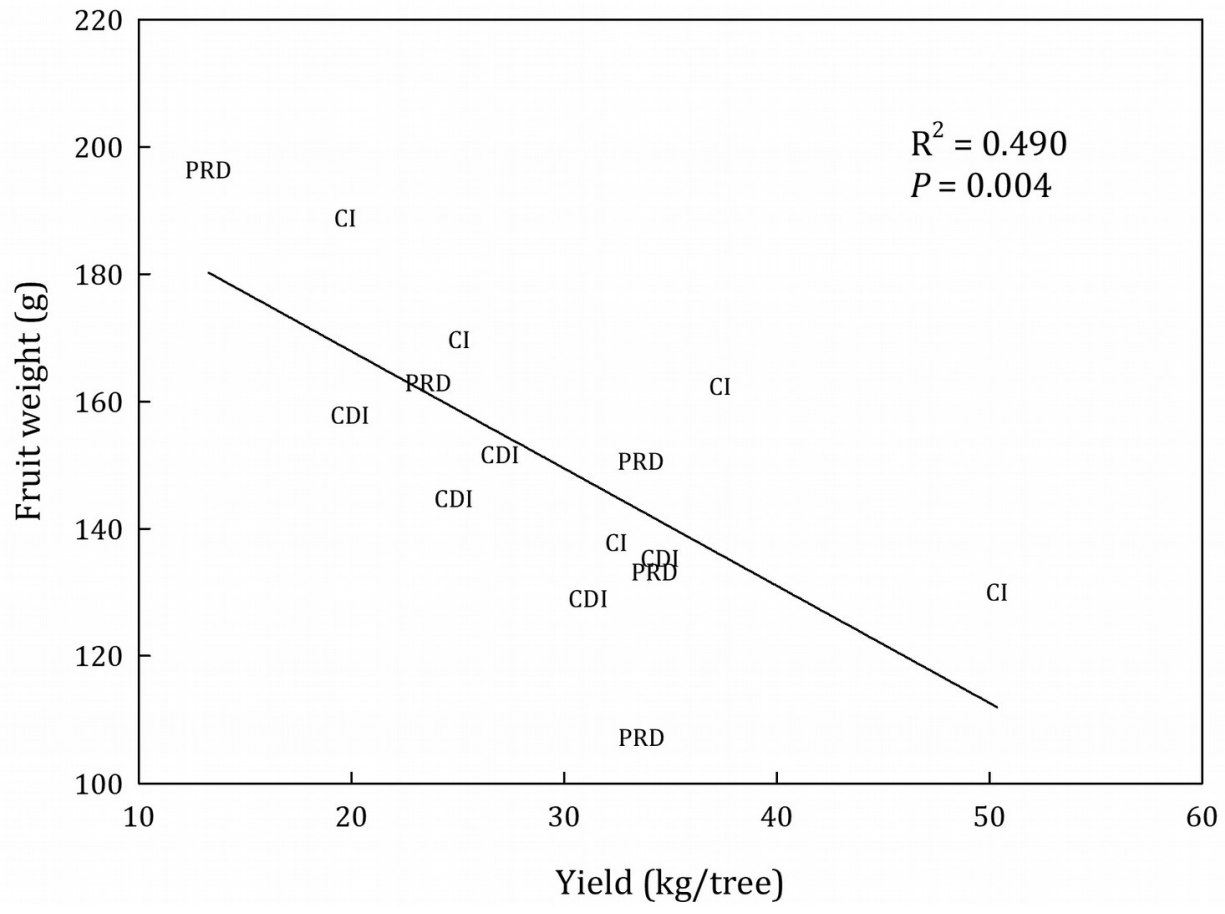

Fig. 2. Relationship between yield and fruit weight of 'Valencia' orange trees under conventional irrigation (CI), partial rootzone drying (PRD) and continuous deficit irrigation (CDI). Data points are averages of the 5 years of trial for each irrigation treatment.

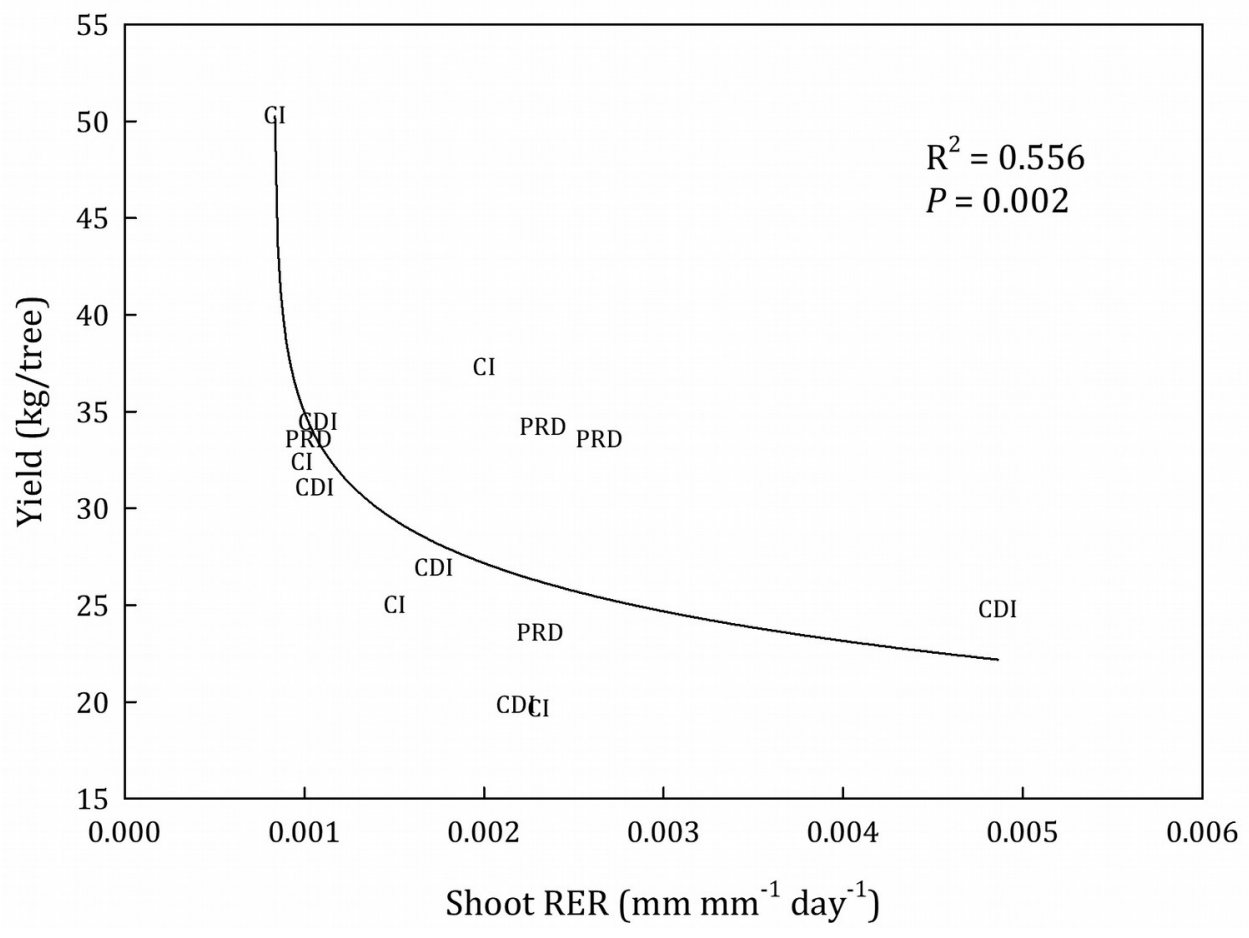

Fig. 3. Relationship between shoot relative elongation rate (RER) and yield of 'Valencia' orange trees under conventional irrigation (CI), partial rootzone drying (PRD) and continuous deficit irrigation (CDI). Data points are averages of the 5 
years of trial for each irrigation treatment. 